\title{
D vitamini testinin akılc kullanımı: Test mi? Ya da tedavi mi?
}

\section{Rational use of vitamin D test: Is it a test? Or treatment?}

\author{
Huri Seval GÖNDEREN ÇAKMAK*@, Yunus Nadi YÜKSEK@ Tanju TÜTÜNCÜ@, Emine Özer KÜÇÜK@ \\ Turan TURHAN D, Dilek BERKER D, Rabia KAHVECI
}

Sağlık Bilimleri Üniversitesi, Numune Eğitim ve Araştırma Hastanesi, SağlıkTeknolojileri Değerlendirme Birimi, Ankara/TÜRKIYE

\section{Öz}

Amaç: : Dünya çapında $D$ vitamini eksikliğinin ve $D$ vitamini test oranlarının artması ile, $D$ vitamininin yetersizliğini yönetme ve gereksiz testleri azaltarak maliyeti düşürme gündeme gelmiştir. Bu çalışmada $D$ vitamini testinin akılcı kullanımı konusunda literatür taraması yapılarak klinik uygulamaya ışık tutmak amaçlanmıştır.

Gereç ve Yöntemler: D vitamini eksiklik prevalansı, tedavi şekilleri ve yaklaşımlar konusunda mevcut durumu ortaya koyabilmek için 2007 Nisan ile 2017 Nisan tarihleri arasında yayınlanmış 4372 çalışma incelenmiştir. Taramalar Cochrane Library, PubMed, Ulakbim, Science Direct elektronik veri tabanları kullanılarak yapılmıştır. Taramalar "Vitamin D status", "Vitamin D screening", "Vitamin D measurements", "Vitamin D Testing", "supplements" anahtar kelimeleri kullanılarak yapılmıştır. Çalışma sınırlarına uyan 74 çalışma değerlendirilmiştir.

Bulgular: D vitamini eksikliği test sayısı ülkemizde ve dünyada giderek önemli bir artış göstermekte ve sağlık bakımına mali yük getirmektedir. D vitamini toksisitesinin az görüldüğü riskli gruplarda D vitamini takviyesine test yapmadan başlanmasının güvenli olduğu ortaya konulmaktadır. Dünyada yayınlanan rehberler D vitamini eksikliği için test yapmak yerine, farkındalığın artıııması, belli gruplarda testsiz D vitamini takviyesi yapıp, belli gruplarda D vitamini testi yapılmasını önermektedir. Depo D vitamini tedavisinden kaçınılması, D vitamini takviyesinin damla olarak kullanılması konusunda farkındalık yaratılması gerekmektedir.

Sonuç: D vitamini damla takviyesinin kanda D vitamini oranına bakılmakıııı, doktor değerlendirmesi ile başlanması çok daha kolay, güvenli ve ucuz bir yaklaşım olarak denenebilir.

Anahtar kelime: D vitamini; D vitamini testi; D vitamini takviyesi

Sorumlu Yazar*: Huri Seval Gönderen Çakmak, Sağlık Bilimleri Üniversitesi, Numune Eğitim ve Araştırma Hastanesi, Sağlık Teknolojileri Değerlendirme Birimi, Ankara/TÜRKIYE

E-posta: sevalgonderen@hotmail.com ORCID: 0000-0003-2980-7804

Gönderim : 05.07.18 Kabul: 14.10.2018

Doi: $10.18663 /$ tjcl.440877 


\section{Abstract}

Aim: The worldwide increase in vitamin $D$ deficiency and vitamin $D$ testing has led to lower vitamin $D$ costs and lower unnecessary testing. In this study, we aimed to shed light on clinical practice by conducting a literature search on the rational use of vitamin $\mathrm{D}$ test.

Material and Methods: 4372 studies published between April 2007 and April 2017 were examined to determine the prevalence, vitamin $D$ deficiency prevalence, treatment modalities and approaches in the world. The scans were made using Cochrane Library, PubMed, Ulakbim, Science Direct electronic databases. The scans were made using the keywords "Vitamin D status", "Vitamin D screening", "Vitamin D measurements", "Vitamin D Testing", "supplements". Finally seventyfour studies that met the study limits were evaluated.

Results: It is found that the number of vitamin D deficiency tests is increasing in our country and in the world, increasing the financial burden on health care. It is demonstrated that it is safe to start vitamin D supplementation without testing in risky groups in which $D$ vitamin toxicity is low. Guidelines published in the world do not refer to test for lack of vitamin $D$, but rather raise awareness, make untested vitamin $D$ supplementation in certain groups, and test for vitamin $D$ in certain groups. Avoidance of high dose vitamin D therapy and awareness of the use of vitamin D supplementation as a drop should be performed.

Conclusion: Regardless of the rate of vitamin $D$, it is much easier, safer and cheaper to start vitamin $D$ supplementation with a doctor's assessment.

Keywords: vitamin D; vitamin D testing; vitamin D supplements

\section{Giriş}

D vitamini yağda eriyen bir sekosteroid prohormondur; önemli bir kısmı (\%80-90)güneş ışığına ultraviyole B (UVB) radyasyona doğrudan maruz kalan ciltte sentez edilir. Aynı zamanda az bir miktarda (\%10-20) besin ile alınabilir. Ciltte sentezlenmesi için doğrudan güneş ışı̆̆ına maruz kalması önemli bir noktadır. Faktör düzeyi 15 veya üzerindeki güneş koruyucu kremlerin kullanılması güneş ışınlarının deriye ulaşmasını engellemektedir. Cam ve tül arkasından güneşlenme de vitamin D sentezini engeller. Güneş ışınlarının dünya yüzeyine ulaştığı açı (Zenith açısı) $D$ vitamini sentezinde etkilidir. Ülkemizin bulunduğu enlemde vitamin D sentezi Mayıs-Kasım ayları arasında gerçekleşir. Uygun ışın açııı saat 10.00-15.00 arasında olduğundan, D vitamini sentezi için bu saatlerde güneşe çıkılması önerilir[1].

D vitamininin günlük ihtiyacını gıdalarla almak oldukça zordur. D vitamini sentezi için en iyi yol güneşe çıkmak yoluyla ciltte sentez edilmesi olsa da, kış ve sonbahar mevsimi, yüksek enlemde bulunan ülkeler, koyu tenli insanlar, UVB etkili güneş kremi kullanan insanlar gibi durumlar nedeniyle $D$ vitamini takviyesi almak gerekmektedir. Kanada, Amerika gibi bazı ülkeler toplumda $D$ vitamini kontrolünü sağlamak için süt, soya sütü, margarin, meyve suyu gibi gıdalara $D$ vitamini katmaktadır[2, 3].

D vitamininin iki formu vardır: bitkisel kaynaklı vitamin D2, hayvansal kaynaklı ve güneş ışığından sentezlenen vitamin D3. Deride yapılan veya diyetle alınan vitamin D2 ve vitamin D3 biyolojik olarak aktif formda değildir. Dolaşımdaki D vitamini, vitamin D bağlayıı protein ile karaciğere taşınmakta ve karaciğerdeki 25 hidroksilaz enzimi ile 25 hidroksivitamin D'ye $[25(\mathrm{OH}) \mathrm{D}$ ] dönüştürülmektedir. Ancak $\mathrm{D}$ vitamininin aktif formuna dönüşmesi böbreklerde gerçekleşmektir. Böbreklerde 1 alfa hidroksilaz ile 1,25 dihidroksivitamin D'ye [1,25(OH)2D] dönüşür. 1 alfa hidroksilaz enzimi $D$ vitamini sentezinde anahtar enzimdir. 25(OH)D ise dolaşımdaki majör formdur, konsantrasyonu 1,25(OH)2D'nin yaklaşık 1000 katıdır ve inaktiftir[4].

D vitamini ince bağırsaktan kalsiyum ve fostat emilimi ve kemik mineralizasyonu, gelişimi ve yeniden şekillenmesini sürdürmek için gerekli temel hormondur. $D$ vitamini postmenopozal kadınlarda ve düşme riski olan yaşlılarda kırık riskini azaltmaktadır. Aynı zamanda son çalışmalar D 
vitamininin hücre proliferasyonunda, apoptozis ve immün sistem için önemli bir vitamin olduğunu göstermektedir. Ayrıca D vitamini eksikliğinin kanser, kardiyovasküler hastalıklar,hipertansiyon, Alzheimer, obezite, tip 1 diyabet gibi hastalıklarla ilişkisi olduğunu belirtilmektedir[5, 6].

Ülkemizden Ankara'da bir hastanede yapılan çalışmanın verilerine göre; oldukça yüksek oranda $(\% 51,8)$ D vitamini eksikliği ve \%20,7 oranında D vitamini yetersizliği tespit edilmiştir[7]. İngiltere'de yakın zamanda yapılan bir çalışmada; kış ve bahar dönemlerinde erişkin popülasyonun \%50'sinden fazlasında D vitamini yetersizliği, \%16'sında da ciddi D vitamini eksikliği saptandığı bildirilmiştir[8]. İsrail'de 2010 yılında genel popülasyonda \%78 oranında (<30ng) D vitamini eksikliği görülmüştür[9]. Avrupa'da yetişkinde Vitamin D eksikliği [serum 25(OH)D <25 nmol/l] \%2-30\% oranında rapor edilirken, huzurevinde kalan yaşlılar için bu oran \%80 oranına çıkmaktadır[10]. Ülkemizde ve dünyada D vitamini eksikliği yaygın bir şekilde görülmekte, D vitamini testi sayısı ve maliyeti giderek artmaktadır. Avustralya'da 2011 yılı içinde D vitamini testi 2000'den 3472,2 (test/100.000 insan) oranına yükselmiş ve bu artış \%59 maliyet artışına sebep olmuştur[11, 12]. Amerika'da 2007-2011 tarihleri arasında 25(OH) D test oranları altı kat artmıştır[13].

Dünya çapında $D$ vitamini eksikliğinin ve $D$ vitamini test oranlarının artması, D vitamininin yetersizliğini yönetme ve gereksiz testleri azaltarak maliyeti düşürme gündeme gelmiştir. Bu çalışmada D vitamini testinin akılcı kullanımı konusunda literatür taraması yapılarak klinik uygulamaya ışık tutmak amaçlanmıştır.

\section{Gereç ve Yöntemler}

D vitamini test kullanımı ile ilgili güncel literatür derlemesi bu bölümde detaylı olarak sunulacaktır. Derlemenin şu sorulara cevap vermesi beklenmektedir:

- D vitaminin optimal değerleri nelerdir?

-Türkiye'de ve dünyada D vitamin eksikliği prevalansı nasıldır?

-D vitamini eksikliği için risk faktörleri nelerdir?

- D vitamini eksikliği belirtileri nelerdir?

- D vitamini toksisitesi nedir?

- D vitamini test uygulamaları nelerdir?

- D vitamini takviyesi uygulama şekilleri nelerdir?
Dünyada D vitamini eksiklik prevalansı, tedavi şekilleri ve yaklaşımlar konusunda mevcut durumu ortaya koyabilmek için 2007 Nisan ile 2017 Nisan tarihleri arasında yayınlanmış 4372 çalışma incelenmiştir. Taramalar Cochrane Library, PubMed, Ulakbim, Science Direct elektronik veri tabanları kullanılarak yapılmıştır. Taramalar "Vitamin D status", "Vitamin D screening", "Vitamin D measurements", "Vitamin D Testing”, "supplements" anahtar kelimeleri kullanılarak yapılmıştır. Araştırma detayları şekil 1 ve 2'de yer almaktadır. Elektronik tarama ile saptanan ilgili tüm yazıların başlık ve özetleri, araştırmacılar tarafından bağımsız olarak gözden geçirilmiştir. Elde edilen çalışmalardan meta-analiz, sistematik derleme, randomize kontrollü çalışma (RKÇ), kontrollü deneysel çalışmalar incelemeye dahil edilmiştir. Çalışma sınırlarına uyan 74 çalışma değerlendirilmiştir.

\section{Araştırmaya dahil edilme kriteri;}

- Yayın dilinin Türkçe ya da İngilizce olması,

• 2007 ile 2017 tarihleri arasında yayınlanmış olması,

- Tam metnine ulaşılabilmesi.

\section{Araştırmaya dahil edilmeme kriteri;}

- Araştırma türü olarak in-vitro çalışmalar, olgu sunumları, devam eden çalışmalar ve tam metnine ulaşılamayan çalışmalar kapsam dışı bırakılmıştır.

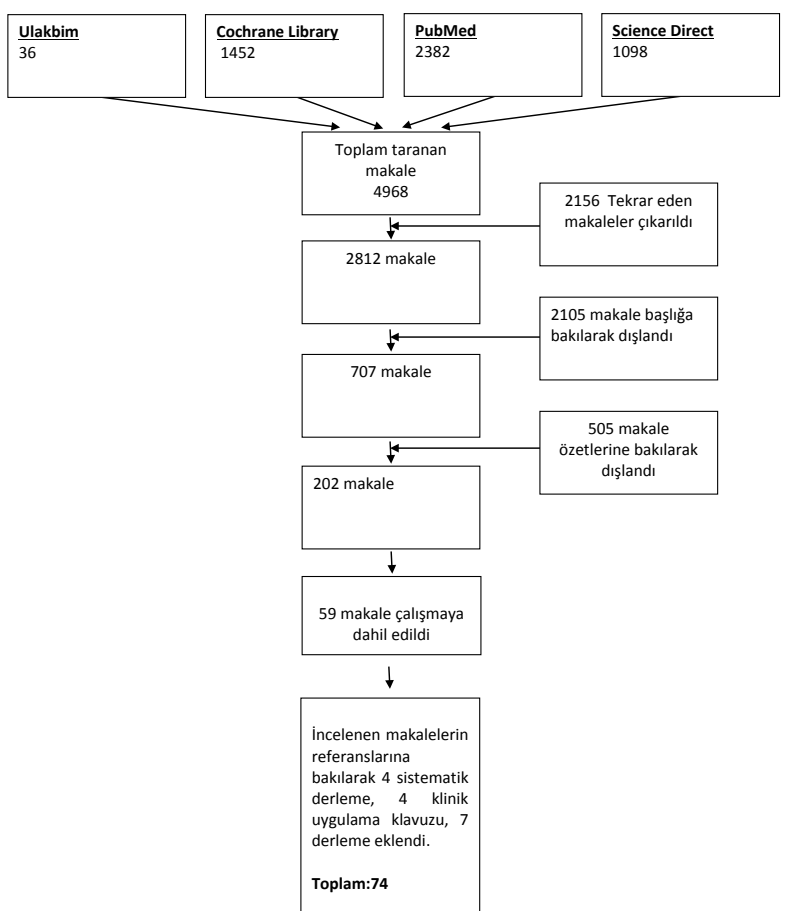

Şekil 1. Araştırma şeması 


\begin{tabular}{|c|c|c|}
\hline Anahtar kelime & Databased & PubMed \\
\hline $\begin{array}{l}\text { vitamin D status } \text { AND } \\
\text { screening AND ("last } 10 \\
\text { years"[PDat] } \\
\text { adult[MeSH]) }\end{array}$ & 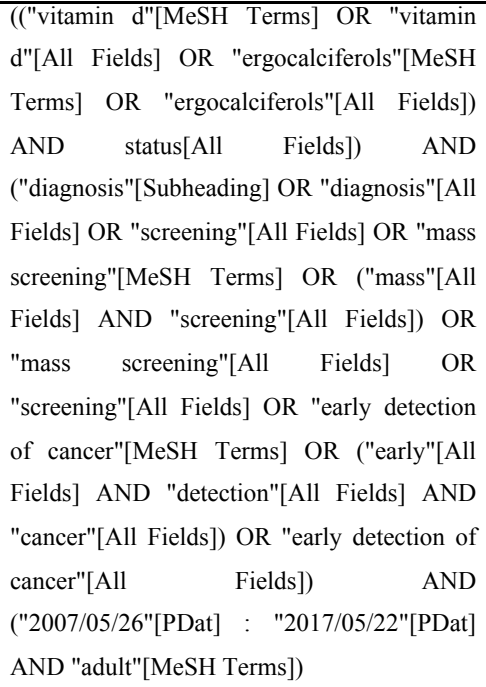 & 719 \\
\hline $\begin{array}{llll}\text { vitamin } & \text { D } & \text { status } & \text { AND } \\
\text { testing } & \text { AND } & \text { ("last } & 10 \\
\text { years"[PDat] } & & \text { AND } \\
\text { adult[MeSH]) } & & \\
\end{array}$ & $\begin{array}{l}\text { (("vitamin d"[MeSH Terms] OR "vitamin } \\
\text { d"[All Fields] OR "ergocalciferols"[MeSH } \\
\text { Terms] OR "ergocalciferols"[All Fields]) } \\
\text { AND status[All Fields]) AND testing[All } \\
\text { Fields] }\end{array}$ & 80 \\
\hline $\begin{array}{l}\text { vitamin D measurements } \\
\text { AND supplements AND } \\
\text { ("last } 10 \text { years"[PDat] } \\
\text { AND adult[MeSH] })\end{array}$ & 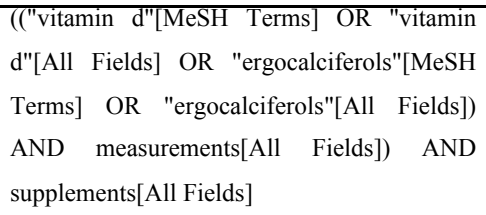 & 161 \\
\hline $\begin{array}{l}\text { vitamin D testing AND } \\
\text { ("last } 10 \text { years"[PDat] } \\
\text { AND adult }[\mathrm{MeSH}])\end{array}$ & $\begin{array}{l}\text { (("vitamin d"[MeSH } \\
\text { d"[All }\end{array}$ & 321 \\
\hline
\end{tabular}

Şekil 2. Tarama Stratejisi

\section{Bulgular}

\section{a) Vitamin D optimal değerleri}

Optimal D vitamini değeri çelişkili olmakla beraber Türk Endokrinoloji ve Metabolizma Derneği'nin Metabolik Kemik Hastalıkları Tanı ve Tedavi Kılavuzunda; serum $25(\mathrm{OH})$ vitamin D düzeyi[1]:

->30 ng/ml durumunda yeterli vitamin D düzeyi,

-20-30 ng/ml vitamin D yetersizliği,

• $10-20 \mathrm{ng} / \mathrm{ml}$ vitamin D eksikliği,

- $<10 \mathrm{ng} / \mathrm{ml}$ ciddi vitamin D eksikliği,

• 25(OH) D düzeyi >150 ng/ml vitamin D intoksikasyonu

olarak tanımlanmıştır.
D vitamin değeri 30ng/ml üzeri yeterli değerlendirilmesine rağmen pek çok kaynak serum D vitamin değerinin 75-100ng/ I arasında olmasını önermektedir[4, 14]. Bazı araştırmalarda serum D vitamin değerinin 50ng/l üzeri olmasını yeterli olarak değerlendirmektedir[15, 16].Vitamin D durumunu değerlendirmek için serum $25(\mathrm{OH})$ vitamin $D$ düzeyi önerilmektedir[2, 12].

\section{b) Vitamin D eksikliği prevalansı}

D vitamini eksikliği çağın pandemisi olarak değerlendirilmekte ve bu konu tüm dünyada "bir sorun" olarak ele alınmakta, çözüm yolları tartışılmaktadır. Toplumda D vitamini eksikliği için pek çok faktör vardır. Bunların başında koyu tenli olmak, güneş kremi kullanımı, gün içinde güneş görmeden çalışmak ya da coğrafi konum alarak yüksek enlemde yaşamak sayılabilmektedir. Ayrıca kronik hastalığa sahip olmak, beş yaş altı çocuklar, yaşlı bireyler, emziren anneler ve gebeler, malabsorbsiyon ile sonuçlanan hastalıklara sahip olan bireyler ve $D$ vitamini metabolizmasını etkileyen ilaç kullanan kişiler D vitamini eksikliği için risk altındadır[2, 14, 15, 17-20]. Ülkemizde ve dünyada vitamin $D$ eksikliği-yetersizliği prevalansları Tablo1'de görülmektedir.

Avrupa Beslenme ve Sağlık Hareketi Anketi'ne (EURONUTSENECA) göre; Güney Avrupa'daki yaşlı bireylerde serum 25 $(\mathrm{OH}) \mathrm{D}$ vitamini 8,01-10,01ng/ml, Kuzey Avrupa'daki kentlerde ise $16,02-20 \mathrm{ng} / \mathrm{ml}$ olarak bulunmuştur[32].Sidney'de bakım evlerinde kalan kadınlarda D vitamini eksikliği prevalansı (ortalama serum 25(OH) D düzeyi $6.8 \mathrm{ng} / \mathrm{ml}^{\prime}$ nin altında) \% 86'dır[32].Avrupa'da yetişkindeVitamin D eksikliği [serum 25(OH) D $<25 \mathrm{nmol} / \mathrm{l}] \% 2-30 \%$ oranında rapor edilirken, huzurevinde kalan yaşlılar için bu oran \%80'lere çıkmaktadır[10].

Bütün bu veriler ışığında dünyada ve ülkemizde genel populasyonda yoğun bir şekilde $D$ vitamini eksikliği veya yetersizliği görüldüğü sonucu çıkabilir. Bu çalışmalar D vitamini eksikliğinin yaygın olduğunu ve bu konuda özel müdahalelere gereksinim duyulduğunu göstermektedir.

\section{c) D Vitamini eksikliği için risk faktörleri}

Tablo 2'de D vitamini eksikliği için risk faktörleri yer almaktadır. Çalışmalar geleneksel risk gruplarının aksine dünya genelinde adölesan ve genç yetişkinlerde de $D$ vitamin eksikliğinin varlığından bahsetmektedir [33-35]. 


\begin{tabular}{|c|c|c|c|c|}
\hline Ülke/yıl & Araştırma populasyonu & $\begin{array}{l}\text { D vitamini } \\
\text { eksikliği }\end{array}$ & $\begin{array}{l}\text { D vitamini } \\
\text { yetersizliği }\end{array}$ & Kabul edilen cut-off değerler \\
\hline Türkiye/ Isparta, 2007[21] & $\begin{array}{l}\text { Kas iskelet sistem ağrısı olan premeno- } \\
\text { pozal kadın } N=68\end{array}$ & $\% 55.9$ & $\% 44.1$ & $25 \mathrm{OHD}<20 \mathrm{ng} / \mathrm{ml}$ \\
\hline Türkiye/ Ankara, 2012[7]. & $18-70$ yaş arası, $\mathrm{N}=513$ & $\% 51,8$ & $\% 20,7$ & $25 \mathrm{OHD}<20 \mathrm{ng} / \mathrm{ml}$ \\
\hline Türkiye/Siirt, 2012[22] & $35-65$ yaş arasında kadın $N=110$ & $\% 20,9$ & $\% 50,9$ & $\begin{array}{l}\text { 25(OH)D düzeyi; } \\
<20 \mathrm{ng} / \mathrm{ml} \text { eksiklik, } \\
\text { 20-29ng/ml yetersizlik, } \\
30 \mathrm{ng} / \mathrm{ml} \text { normal, } \\
>150-200 \mathrm{ng} / \mathrm{ml} \text { intoksikasyon }\end{array}$ \\
\hline Türkiye/ Malatya, 2013[23] & 20 yaş ve üzeri kadın $N=381$ & $\% 10.9$ & $\% 80,2$ & $\begin{array}{l}\text { 25(OH)D düzeyi; } \\
<5 \mathrm{ng} / \mathrm{ml} \text { ciddi eksiklik, } \\
5-15 \mathrm{ng} / \mathrm{ml} \text { orta düzey eksiklik, } \\
\text { 15-30ng/ml eksiklik, } \\
>30 \mathrm{ng} / \mathrm{ml} \text { normal düzey, }\end{array}$ \\
\hline Ingiltere, 2006[24] & $\begin{array}{l}\text { Yaş ortalamaları } 15.3 \text { olan kız } \\
\text { çokçukları } N=182\end{array}$ & $\% 73$ & $\% 17$ & $\begin{array}{l}\text { 25(OH)D düzeyi; } \\
<12.5 \mathrm{nmol} / / \text { yetersizlik } \\
<30 \mathrm{nmol} / \mathrm{l} \text { eksiklik }\end{array}$ \\
\hline İtalya, 2007[25] & Yaş ortalaması 7.2 olan çocuklar N=192 & $\% 6,2$ & - & $25 \mathrm{OHD}<25 \mathrm{nmol} / \mathrm{L}$ \\
\hline Hindistan, 2009[26] & Adolesan/ Çocuk N=121 & $\% 88,6$ & - & $25 \mathrm{OHD}<50 \mathrm{nmol} / \mathrm{l}$ \\
\hline İsrail, 2010 [9] & 18 yaş üzeri, Sağlıklı gönüllüler N=195 & $\% 78$ & $\% 20$ & $25 \mathrm{OHD}<30 \mathrm{ng} / \mathrm{lml}$ \\
\hline Pakistan, 2010[27] & 18 yaş üzeri $\mathrm{N}=123$ & $\% 69,9$ & $\% 21,1$ & $25 \mathrm{OHD}<50 \mathrm{nmol} / \mathrm{L}$ \\
\hline Danimarka, $2011[28]$ & Sağlıklı 9 aydan büyük çocuklar N=255 & $\% 11$ & - & $25 \mathrm{OHD}<50 \mathrm{nmol} / \mathrm{L}$ \\
\hline Avusturalya, 2012[29] & $25-95$ yaş arası birey $\mathrm{N}=11.218$ & $\% 4$ & $\% 31$ & $25 \mathrm{OHD}<50 \mathrm{nmol} / \mathrm{l}$ \\
\hline İlanda, 2015[30] & $7-11$ yaş çocuk $N=297$ & $\% 31$ & $\% 65$ & $25 \mathrm{OHD}<20 \mathrm{ng} / \mathrm{ml}$ \\
\hline Hollanda, 2015[31]. & Okul çağı çocuklar N=4167 & $\% 23,6$ & $\% 66,7$ & $\begin{array}{l}25(\mathrm{OH}) \mathrm{D} \text { düzeyi; } \\
<25 \mathrm{nmol} / \mathrm{L} \text { ciddi eksiklik, } \\
25 \mathrm{to}<50 \mathrm{nmol} / \mathrm{L} \text { eksiklik, } \\
\geq 75 \mathrm{nmol} / \mathrm{L} \text { normal }\end{array}$ \\
\hline
\end{tabular}

Tablo 2. D Vitamini eksikliği için risk faktörleri $[2,15,17-20,36,37]$

$\begin{array}{lll}\text { Güneş Maruziyetinde Azalma } & \text { Diyet } & \text { Yaş ve Hastalık Durumu } \\ \text { - Yaşlılık } & \text { - Uzun emzirme dönemi } & \text { - Obezite } \\ \text { - Koyu cilt rengi } & \text { - Balık, yumurta tüketiminin az } & \text { - Yaşlılık } \\ \text { - Kış mevsimi } & \text { olması, } & \text { - Kronik böbrek hastalığı } \\ \text { - Vardiyalı ve kapalı ortamda çalışma } & & \text { - Malabsorpsiyon sendromu(Crohn hastalığı, } \\ \text { - Kapalı giyim tarzı } & & \text { kistik fibrozis, karaciğer hastalığı) } \\ \text { - Güneş kremi kullanımı } & & \text { - Absorbsiyonu azaltan ilaç kullanımı }\end{array}$

\section{d) D Vitamini eksikliği belirtileri}

Klinik bulgular vitamin D eksikliğinin derecesi ve süresine bağlıdır. Çoğu hasta asemptomatiktir ve serum kalsiyum, fosfor ve alkalen fosfataz düzeyi bu hastalarda normaldir [1]. Çocukluk ve yetişkinlik dönemi için D vitamin eksikliğinin genel belirtileri Tablo 3'de yer almaktadır.

\begin{tabular}{|c|c|}
\hline Yaş grubu & Belirtiler \\
\hline Çocuk & $\begin{array}{l}\text { - } 6 \text { aydan sonra kemik deformitesi( ricket } \\
\text { görülmesi), } \\
\text { - Bacaklarda eğiklik, } \\
\text { - Gelişme bozukluğu, } \\
\text { - Çocukta huzursuzluk, } \\
\text { - Raşitik akciğer( esnek göğus kafesi ve kuv- } \\
\text { vetsiz kaslar) }\end{array}$ \\
\hline Yetişkin & $\begin{array}{l}\text { - Kas iskelet ağrısı, } \\
\text { - Kaburga, kalça, pelvis, uyluk ve ayak ağrısı } \\
\text { - Halsizlik, kuvvetsizlik } \\
\text { - Osteomalazi } \\
\text { - Depresyona eğilim } \\
\text { - Kırık }\end{array}$ \\
\hline
\end{tabular}




\section{e) D Vitamini toksisitesi}

TürkEndokrinolojiveMetabolizma derneğinin MetabolikKemik Hastalıkları Tanı ve Tedavi Kılavuzunda; Serum 25(OH) vitamin D düzeyi>150 ng/ml üzeri toksisite olarak değerlendirirken, bazı kaynaklar $>200 \mathrm{ng} / \mathrm{ml}$ üzerini toksisite olarak değerlendirmektedir[1, 38]. Çalışmalar incelendiğinde;28 yıldır, günde 150.000 IU D2 vitamini alan bir kadında toksisite saptanmadığı bildirilmiştir[39]. Aynı zamanda 5 aylık süre zarfında günlük 10.000IU Vitamin D3 alan bir yetişkinin bu dozu tolere edebildiği görülmüştür[40].D vitamini- kalsiyum kombinasyonu kullanımı böbrek taşı riskini artırabilmekte ama yalnız D vitamini takviyesi kullanımı böbrek taşı ve $D$ vitamini toksisitesi için risk oluşturmamaktadır[41]. Görüldüğü gibi literatürde ve klinik uygulamalarda D vitamini takviyesine bağlı toksisitenin yaygın görülmediği rapor edilmiştir[17, 42]. $\mathrm{Bu}$ durum genel populasyonda test yapmadan $\mathrm{D}$ vitamini takviyesi başlanabileceği konusunda kanıt oluşturabilir.

D vitamini toksisitesi yaygın olmamakla beraber klinikte bulantı, kusma, konstipasyon, kilo kaybı gibi spesifik olmayan belirtilerle kendini gösterir[1].

\section{f) D Vitamini testi uygulamaları}

Türk Endokrinoloji ve Metabolizma Derneği'nin Metabolik Kemik Hastalıkları Tanı ve Tedavi Kılavuzuna göre; vitamin D durumu, serum 25(OH) D düzeyi ölçümü ile değerlendirilir. 25(OH) D’nin yarı ömrü 2-3 haftadır. 1,25-dihidroksi Vitamin D'nin yarı ömrünün 4 saat gibi kısa olması, kan konsantrasyonunun çok düşük olması nedeniyle, vitamin D durumu hakkında çok iyi bilgi vermemektedir. Bu nedenle, vitamin D eksikliği tanısında kullanılması önerilmemektedir.
25(OH) D, yüksek performanslı sıvı kromatografisi (HPLC), sıvı kromatografi/tandem mass spectrometry (LC/MS) yöntemleri ile ölçülmesi güvenilir olduğu belirtilmiştir[1].

Dünyadaki test uygulama şekilleri incelendiğinde, Avustralya'da 2006-2010 yılları arasında 4,5 milyon D vitamini testi yapılmıştır. D vitamini testlerinin \%80'i pratisyen hekimler tarafından, \%20'si uzman hekimler tarafından istenmiştir. Yapılan toplam D vitamini testlerinin \%11' i ise üçüncü defa test edilmiştir. Aynı yıllarda kişi başı D vitamini test istem sıklığı 2-4 test/kişi arasında değişip, artış göstermiştir. Hekimlerin istem yapma oranlar ıpratisyen hekimlerde \%71'den \%85'e, uzman hekimlerde \%15'den \%27'e yükselmiştir[11, 12]. Avusturalya'da 2011 yılı içinde D vitamini testi 2000 den 3472,2 (test/100.000 insan) oranına yükselmiş ve bu artış \%59 maliyet artışına sebep olmuştur[43]. Amerika Birleşik Devletleri'nde 2007-2011 tarihleri arasında 25(OH) D test oranları altı kat artmıştır[13].Ülkemizde D vitamini test istem maliyetleri ile ilgili bir çalışmaya rastlanmamıştır.

\section{g) D Vitamini testi uygulama önerileri}

Artan maliyet ve test sayılarını takiben, gereksiz test ve buna bağlı maliyetleri azaltmak amaçlı Kanada, İngiltere ve Avusturalya başta olmak üzere her ülke kendi $D$ vitamini test uygulama standartını geliştirmeye çalışmış ve klinik rehberlerde önerilerde bulunmuştur. Tablo 4'de ülkelerin ve rehberlerin Vitamin D test uygulama önerileri görülmektedir.

Gereksiz D vitamin ölçümlerini azaltmak amacı ile kanıta dayalı rehberler, belirli hastalık gruplarında D vitamini ölçülmesini önermektedir. Vitamin D ölçümü yapılması önerilen durumlar Tablo 5'de özetlenmiştir.

\begin{tabular}{|c|c|c|c|}
\hline Çalışma/yıl & ülke & Populasyon & Rutin test \\
\hline $\begin{array}{l}\text { The American College of } \\
\text { Obstetricians and Gynecolo- } \\
\text { gists, } 2011[19] .\end{array}$ & $\begin{array}{l}\text { Amerika Birleşik } \\
\text { Devletleri }\end{array}$ & $\begin{array}{l}\text { D vitamini takviyesi kullanırken rutin test ve tüm gebelerde } \\
\text { rutin ölçüm önerilmemektedir }\end{array}$ & Önerilmiyor \\
\hline $\begin{array}{l}\text { International Organization } \\
\text { for Migration(IOM), 2011[44] }\end{array}$ & $\begin{array}{l}\text { Amerika Birleşik } \\
\text { Devletleri ve } \\
\text { Kanada }\end{array}$ & \multirow{3}{*}{$\begin{array}{l}\text { Riskli gruplarda D vitamini takviyesi yapılarak, D vitamini } \\
\text { eksikliği için test oranları azaltılmasını, hamile ve doğumdan } 5 \\
\text { yaşa kadar D vitamini takviyesinin alınmasını, asemptomatik } \\
\text { seyreden risk gruplarında testsiz D vitamini takviyesi, düzenli } \\
\text { güneş ışığına çıkılması ve diyet kaynaklarının tüketilmesini, } \\
\text { sadece semptomatik bireylerde D vitamini testi yapılarak } \\
\text { tedavi düzenlemesini önermektedir }\end{array}$} & \multirow{3}{*}{ Önerilmiyor } \\
\hline $\begin{array}{l}\text { Avusturalya Test Rehberi, } \\
2012[12,43]\end{array}$ & Avusturalya & & \\
\hline NICE guideline, 2015[45] & Ingiltere & & \\
\hline $\begin{array}{l}\text { Avusturalya Test Rehberi } \\
2012,2013[11,12]\end{array}$ & Avusturalya & $\begin{array}{l}\text { Ölçüm yapılması zorunlu durumlarda İlki tanı, ikinci } 3 \text { aylık } \\
\text { vitamin takviyesini izlemek, üçüncüsü vitamin takviyesinden } 6 \\
\text { ay sonra izlem olarak yılda en fazla üç test önermektedir }\end{array}$ & Önerilmiyor \\
\hline $\begin{array}{l}\text { Kanada ilaç ve sağlık } \\
\text { teknolojileri değerlendirme } \\
\text { rehberi , 2015[46] }\end{array}$ & Kanada & Semptomatik D vitamin eksikliğinde test önerilmektedir. & Önerilmiyor \\
\hline
\end{tabular}




Tablo 5. D Vitamini ölçümü yapılması önerilen durumlar[1,
2, 15, 17-20,47]:
- Malabsorbsiyon Sendromu
- Böbrek Yetmezliği
- Açıklanamayan Kemik Ağrısı
- Anormal Kırıklar
- Metabolik Kemik Hastalıkları
- Kalıtımsal fosfat kaybettiren hastalıklar
- Onkojenik osteomalasi
- serum alkalin fosfat seviyesinde açıklanamayan yükselme
- Hipo/hiperparatiroidizm
- Hipo/hiperkalsemi/fosfotemi

\section{h) D Vitamini Takviyesi Kullanımı}

Çağın pandemisi olarak değerlendirilen D vitamini eksikliği ile baş etmek ve genel toplumun sağlığını yükseltmek amacı ile test yapılmadan kullanılabilecek D vitamini dozları gündeme gelmiştir. NICE D vitamini ile ilgili; bütün sağlık profesyonellerinin D vitamini takviyesi alımını önermesini sağlamak, Vitamin D takviyesine erişimin sağlanması, riskli gruplar için vitamin D ulaşılabilirliğinin yükseltilmesi, sağlıklı başlangıç takviyesinin geliştirilmesi(her hamile, süt veren ve 5 yaş altı çocuk), yüksek riskli ya da semptomatik kişilerde yalnız bir kere test yapılması, D vitamininin önemi konusunda farkındalığın geliştirilmesi, D vitamini takviyesi alımlarında izlem ve değerlendirme kayıtları yapılması, her yaş grubu için D vitamini yaklaşımının geliştirilmesi önerilerinde bulunmuştur[45]. Ayrıca kadınlarda günlük 800IU D vitamini ve $>1000$ mgr Kalsiyum alımının tek başına düşme ve kırık riskini azalttığını ortaya koymuştur ve D vitamini takviyesi alımını önermiştir[48-50].

Bunların dışında bazı ülkeler D vitamini takviyesi için kullanım önerileri geliştirmişlerdir. Ülkelerin D vitamini takviyesi kullanım önerileri Tablo 6'da özetlenmiştir.

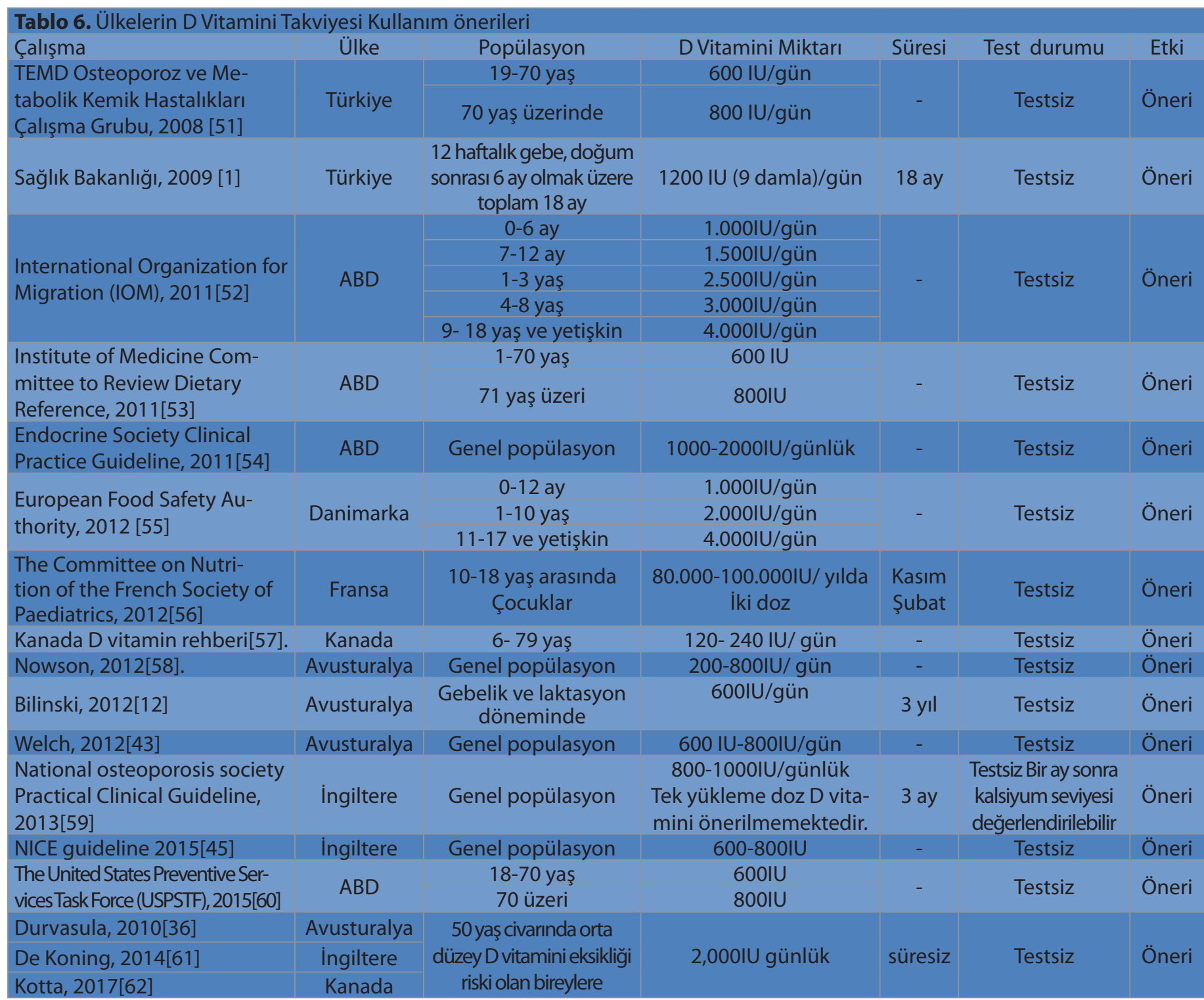

TEMD: Türkiye Endokrin ve Metobolizma Derneği, ABD: Amerike Birleşik Devletleri 
Çalışmalar incelendiğinde; tedavi uygulamasında 25-(OH)D seviyesinin 8 haftada plato değerine ulaştığı ve yükselişten sonra günlük her 40IU D vitamini takviyesinin $0,7 \mathrm{nmol} / \mathrm{L}$ artış sağladığı gösterilmişti[63, 64]. Ayrıca günlük alınan 1000IU D vitamininin, 8 haftalık süre içinde yaklaşık $17 \mathrm{nmol} / \mathrm{L}$ değerinde bir yükselme sağladığı saptanmıştır [64]. Genel popülasyonda günlük 6100IU vitamin $D$ takvisinin toksisite geliştirmeden kan 25(OH)D seviyesini 74nmol/L'e çıkardığı raporlanmıştır[65]. Bu noktada D vitamini takviyesinin sadece kanda 25(OH)D seviyesini mi düzelttiği, klinik olarak da fayda sağlayıp sağlamadığı sorusu akla gelmiştir. Bu konuda yapılan çalışmalar incelendiğinde, $D$ vitamini takviyesinin sadece kan 25(OH)D seviyesini değiştirmediği, aynı zamanda klinik iyileşme de sağladığı görülmektedir. Tablo 7'de $D$ vitamini takviyesi içeren çalışmaların sonuçları özetlenmektedir.

\begin{tabular}{|c|c|c|c|c|c|}
\hline Çalışma/yıl/Ülke & Çalışma tipi & Çalışma Grubu & DVitamini(miktar/gün) & $\begin{array}{l}\text { İzlem } \\
\text { süresi }\end{array}$ & Sonuç \\
\hline $\begin{array}{l}\text { Mai ve arkadaşları, } \\
2017 /[66] \\
\text { (italya) }\end{array}$ & $\begin{array}{l}\text { Randomize kon- } \\
\text { trollü çalışma }\end{array}$ & $\begin{array}{c}\mathrm{BMI}>40 \mathrm{~kg} / \mathrm{m} 2 \text { olan } \\
\mathrm{N}=12\end{array}$ & 600,000IU/gün & 4 hafta & $\begin{array}{l}\text { HMW-A ve leptin/HMW-A } \\
\text { oranı değiştirdi. }\end{array}$ \\
\hline $\begin{array}{l}\text { Majid ve arkadaşları, } \\
\text { 2017[67] } \\
\text { (İan) }\end{array}$ & $\begin{array}{l}\text { Çiftkör, random- } \\
\text { ize kontrollü } \\
\text { çalışma }\end{array}$ & $\begin{array}{l}20-50 \text { yaş, uyku prob- } \\
\text { lemi yaşayan bireyler } \\
\qquad N=89\end{array}$ & 50.000IU/gün & 8 hafta & $\begin{array}{l}\text { Uyku kalitesi gelişti, uykuya } \\
\text { dalma süresi azaldı, uyku } \\
\text { süresi arttı. }\end{array}$ \\
\hline $\begin{array}{l}\text { Bilici M, } 2016 \text { [68]. } \\
\text { (Türkiye) }\end{array}$ & Kesitsel çalışma & $\begin{array}{c}\text { 10-18 yaş D vitamin } \\
\text { eksikliği olan adolesan } \\
\mathrm{N}=97\end{array}$ & 2000 IU/gün & 3 ay & $\begin{array}{l}\text { Diyastolik kan basıncı, total } \\
\text { kolesterol ve trigliserid düzey- } \\
\text { inde azalma, } \\
\text { interlökin-6 düzeyinde azalma }\end{array}$ \\
\hline $\begin{array}{l}\text { Tambova A, } 2015 \text { [69]. } \\
\text { (Türkiye) }\end{array}$ & Kesitsel çalışma & $\begin{array}{c}\text { Vitamin } \mathrm{D}(<20 \mathrm{ng} / \mathrm{ml} \\
\text { ) olan kronik böbrek } \\
\text { hastası } \\
\mathrm{N}=82\end{array}$ & $50.000 I U /$ hafta & 8 hafta & $\begin{array}{l}\text { Trombosit agregasyonunda } \\
\text { düşme }\end{array}$ \\
\hline $\begin{array}{l}\text { Moreira-Pfrimer ve } \\
\text { arkadaşları, 2009[70] } \\
\text { (Brezilya) }\end{array}$ & $\begin{array}{l}\text { Çift kör random- } \\
\text { ize kontrollü } \\
\text { çalışma }\end{array}$ & $\begin{array}{c}60 \text { yaş üzeri bireyler } \\
\qquad \mathrm{N}=102\end{array}$ & $\begin{array}{l}\text { Illk } 2 \text { ay } 150.000 \mathrm{IU} / \\
\text { gün, } \\
\text { son } 4 \text { ay } 90.000 \mathrm{IU} / \\
\text { gün }\end{array}$ & 6 ay & $\begin{array}{l}\text { Bu kullanım D vitamini sevi- } \\
\text { yesini yükseltmek için güvenli } \\
\text { ve etkili, } \\
\text { Yaşııarın ekstremite kas kuv- } \\
\text { veti artmakta }\end{array}$ \\
\hline $\begin{array}{l}\text { Gallagher ve } \\
\text { arkadaşları, 2012[71] } \\
\text { (Nebraska) }\end{array}$ & $\begin{array}{c}\text { Randomize, } \\
\text { plasebo kontrollü } \\
\text { çalışma }\end{array}$ & $\begin{array}{l}\text { Postmenopozal beyaz } \\
\text { kadın } \\
\mathrm{N}=163\end{array}$ & $\begin{array}{l}400,800,1600 \\
2400,3200,4000 \\
4800 \text { IU/gün }\end{array}$ & 12 ay & $\begin{array}{c}\text { \%97,5 kadının D vitamini kan } \\
\text { seviyesi } 800 \text { IU ile yükseldi. } \\
\text { Bu sonuç yaş gruplarına } \\
\text { genellenemez }\end{array}$ \\
\hline $\begin{array}{l}\text { Dong ve arkadaşları } \\
2010[72] \\
\text { (Avusturalya) }\end{array}$ & $\begin{array}{l}\text { Randomize kon- } \\
\text { trollü çalışma }\end{array}$ & $\begin{array}{l}\text { Yaş ortalaması } 16 \text { olan } \\
\text { kız ve erkek çocuklar } \\
\qquad N=49\end{array}$ & $\begin{array}{l}n=24 / 400 \text { IU/gün } \\
n=25 / 2.000 I U / g u ̈ n\end{array}$ & 16hafta & $\begin{array}{l}\text { Günlük 2000IU D vitamini } \\
\text { takviyesi optimal D vitamini } \\
\text { seviyesi için etkilidir ve aort } \\
\text { sertliğinin ilerlemesini ve } \\
\text { yaşlanmayı engellemektedir. }\end{array}$ \\
\hline $\begin{array}{l}\text { Ganmaa ve } \\
\text { arkadaşları, 2017[73] } \\
\text { (Moğolistan) }\end{array}$ & $\begin{array}{l}\text { Çift kör random- } \\
\text { ize kontrollü } \\
\text { çalışma }\end{array}$ & $\begin{array}{c}12-15 \text { yaş } \\
\text { Çocuklar } \\
\mathrm{N}=113 \\
9-11 \text { yaş çocuk } \\
\mathrm{N}=235\end{array}$ & $\begin{array}{c}800 I U / g u ̈ n \\
710 \text { cc süt/300IU } \\
\text { içerikli/gün }\end{array}$ & 7 hafta & $\begin{array}{l}\text { 800IU/gün D vitamini takviyesi } \\
\text { çocukların kan seviyelerinde } \\
\text { yeterli yükselme sağlamıştır. }\end{array}$ \\
\hline
\end{tabular}

\section{Sonuç}

D vitamini eksikliği ve yetersizliği dünyada çağın pandemisi olarak değerlendirilmektedir. Ülkemizde ve dünyada her yaş grubunda yaygın olarak D vitamini eksikliği veya yetersizliği görülmektedir. D vitamini eksikliği ve yetersizliğinin kemik sağlığını olumsuz etkilemenin dışında kanser, hipertansiyon, diyabet, obezite, hamilelerde erken doğum ve eklemsi gelişimi gibi birçok hastalığa yol açtığı meta-analizler sonucunda görülmektedir. D vitamini eksikliği test sayısı ülkemizde ve dünyada giderek önemli bir artış göstermekte ve sağlık bakımına mali yük getirmektedir. D vitamini toksisitesinin az görüldüğü riskli gruplarda $D$ vitamini takviyesine test yapmadan başlanmasının güvenli olduğu ortaya konulmaktadır. 
Dünyada yayınlanan rehberler D vitamini eksikliği için test yapmak yerine, farkındalığın artırılması, belli gruplarda testsiz D vitamini takviyesi yapıp, belli gruplarda D vitamini testi yapılmasını önermektedir. Depo D vitamini tedavisinden kaçınılması, D vitamini takviyesinin damla olarak kullanılması konusunda farkındalık yaratılması gerekmektedir. D vitamini damla takviyesinin kanda D vitamini oranına bakılmaksızın, doktor değerlendirmesi ile başlanması çok daha kolay, güvenli ve ucuz bir yaklaşım olarak denenebilir.

\section{Çıkar çatışması / finansal destek beyanı}

Bu yazıdaki hiçbir yazarın herhangi bir çıkar çatışması yoktur. Yazının herhangi bir finansal desteği yoktur

\section{Kaynaklar}

1. Metabolik Sendrom Kılavuzu, Türkiye Endokrinoloji ve Metabolizma Derneği. Ankara, Tuna Matbaacılık, 2009: 8-11.

2. Calvo MS, Whiting SJ, Barton CN, Vitamin D fortification in the United States and Canada: current status and data needs. The American Journal of Clinical Nutrition 2004; 80: 1710-16.

3. Yetley EA, Assessing the vitamin D status of the US population. The American Journal of Clinical Nutrition 2008; 88: 558-64.

4. Holick MF.Vitamin D deficiency. New England Journal of Medicine 2007; 357: 266-81.

5. Karami S, Colt JS, Stewart PA et al. A case-control study of occupational sunlight exposure and renal cancer risk. International Journal of Cancer 2016; 138: 1626-33.

6. Mokry LE, Ross S, Morris JA, Manousaki D, Forgetta V, Richards JB. Genetically decreased vitamin $d$ and risk of alzheimer disease. Neurology 2016; 87: 2567-74.

7. Uçar F, Taşlıpınar MY, Soydaş AÖ, Özcan N. Ankara etlik ihtisas eğitim ve araştırma hastanesine başvuran hastalarda 25-oh vitamin d düzeyleri. Eur J Basic Med Sci 2012; 2: 12-15.

8. Pearce $S$, Cheetham TD. Diagnosis and management of vitamin d deficiency.Bmj, 2010; 340: 5664

9. Oren $\mathrm{Y}$, Shapira $\mathrm{Y}$, Agmon-Levin $\mathrm{N}$ et al. Vitamin d insufficiency in a sunny environment: a demographic and seasonal analysis. IMAJ-Israel Medical Association Journal 2010; 12: 751.

10. Lips P. Vitamin $d$ status and nutrition in europe and asia.The Journal Of Steroid Biochemistry and Molecular Biology, 2007; 103: $620-25$

11. Bilinski $K$, BoyagesS.Evidence of overtesting for vitamin $D$ in Australia: an analysis of 4.5 years of Medicare Benefits Schedule (MBS) data. BMJ open 2013; 3: 2955.
12. Bilinski $\mathrm{KL}$, Boyages $\mathrm{S} C$. The rising cost of vitamin $\mathrm{D}$ testing in Australia: time to establish guidelines for testing. Med J Aust 2012; 197: 90.

13. Sattar N, Welsh P, Panarelli M, Forouhi NG. Increasing requests for vitamin $D$ measurement: costly, confusing, and without credibility. The Lancet 2012; 379: 95-96.

14. van Schoor NM, LipsP.Worldwide vitamin D status. Best Pract Res Clin Endocrinol Metab 2011; 25: 671-80.

15. Ross AC, Manson JE, Abrams SA et al.The 2011 report on dietary reference intakes for calcium and vitamin $D$ from the Institute of Medicine: what clinicians need to know. The Journal of Clinical Endocrinology \& Metabolism 2011; 96:53-58.

16. Aspray TJ, Bowring C, Fraser W et al. National osteoporosis society vitamin D guideline summary. Age and ageing 2014; 43: 592-95.

17. Briot K, Audran M, Cortet B et al. Vitamin D: skeletal and extra skeletal effects; recommendations for good practice. Presse medicale (Paris, France: 1983), 2009; 38: 43-54.

18. Francis R. Vitamin $D$ and bone health: a practical clinical guideline for patient management. National Osteoporosis Society, 2013.

19. ACOG Committee Opinion No. 495: Vitamin D: Screening and supplementation during pregnancy. Obstetrics and gynecology 2011; 118: 197.

20. Souberbielle JC, Body JJ, Lappe JM, Plebaniet M. Vitamin D and musculoskeletal health, cardiovascular disease, autoimmunity and cancer: recommendations for clinical practice. Autoimmunity reviews 2010; 9: 709-15.

21. Yener M. Kas iskelet sistem ağrısı ile vitamin $D$ düzeyleri arasındaki ilişkinin araştırılması. SDÜ Tıp Fakültesi Dergisi 2007; 14.

22. Akpınar $P$, İçağasıoğluA, D vitamininin yaşam kalitesi ile ilişkisi. Türk Osteoporoz Dergisi 2012; 18: 13-18.

23. Koluaçık Yıldırım S. Malatya il merkezinde 20 yaş ve üzeri kadınlarda d vitamini düzeyi ile üst solunum yolu enfeksiyonları arasındaki ilişki. Doktora Tezi, İnönü Üniversitesi Sağlık Bilimleri Enstitüsü, Malatya; 2013.

24. Das G, Crocombe S, McGrath M, BerryJL.Hypovitaminosis D among healthy adolescent girls attending an inner city school. Arch Dis Child 2006; 91: 569-72.

25. Lippi G,MontagnanaM, TargherG, Vitamin D deficiency among Italian children. Cmaj 2007; 177: 1529-30.

26. Sahu M, Bhatia V, Aggarwal A et al. Vitamin D deficiency in rural girls and pregnant women despite abundant sunshine in northern India. Clin Endocrinol (Oxf) 2009; 70: 680-84. 
27. Mansoor S, Habib A, Ghani F et al. Prevalence and significance of vitamin D deficiency and insufficiency among apparently healthy adults. Clinical biochemistry 2010; 43: 1431-35.

28. Østergård M, Arnberg K, Michaelsenet KF et al. Vitamin D status in infants: relation to nutrition and season. Eur J Clin Nutr 2011 65: 657-60

29. Daly RM, Gagnon C, Lu ZX, Magliano DJ. Prevalence of vitamin $D$ deficiency and its determinants in Australian adults aged 25 years and older: a national, population-based study. Clin Endocrinol (Oxf) 2012; 77: 26-35.

30. Mellati AA, Sharifi F, Faghihzade $S$ et al. Vitamin D status and its associations with components of metabolic syndrome in healthy children. Journal of Pediatric Endocrinology and Metabolism 2015; 28: 641-48.

31. Voortman $\mathrm{T}$, van den Hoovenet $\mathrm{EH}$ et al. Vitamin $\mathrm{D}$ deficiency in school-age children is associated with sociodemographic and lifestyle factors. The Journal of nutrition 2015; 145: 791-798.

32. Mithal A, Wahl DA, Bonjour JP, Burckhardt P. Global vitamin D status and determinants of hypovitaminosis D. Osteoporosis International 2009; 20: 1807-20.

33. Forrest $\mathrm{KY}$, Stuhldreher WL.Prevalence and correlates of vitamin D deficiency in US adults. Nutrition Research 2011; 31: 48-54.

34. Ginde AA, Liu MC, Camargo CA, Demographic differences and trends of vitamin D insufficiency in the US population, 19882004. Archives of İnternal Medicine 2009; 169: 626-32.

35. Ginde AA, Sullivan AF, MansbachJM et al. Vitamin D insufficiency in pregnant and nonpregnant women of childbearing age in the United States. American Journal of Obstetrics and Gynecology 2010; 202: 436-38.

36. Durvasula S, Kok C, Sambrook PN et al. Sunlight and health: attitudes of older people living in intermediate care facilities in southern Australia. Archives of Gerontology and Geriatrics 2010; 51: 94-99.

37. Sohl E, van Schoor NM, de JonghRT et al. The impact of medication on vitamin $\mathrm{D}$ status in older individuals. European Journal of Endocrinology 2012; 166: 477-85.

38. Jones G. Pharmacokinetics of vitamin D toxicity. The American Journal Of Clinical Nutrition 2008; 88: 582-86.

39. Stephenson DW, Peiris AN.The lack of vitamin D toxicity with megadose of daily ergocalciferol (D2) therapy: a case report and literature review. Southern Medical Journal 2009; 102: 765-68.

40. Hathcock JN, Shao A, ViethR and et al. Risk assessment for vitamin D. The American Journal of Clinical Nutrition 2007; 85: 6-18.
41. Lefevre M L. Screening for Vitamin D Deficiency in Adults: US Preventive Services Task Force Recommendation StatementScreening for Vitamin D Deficiency in Adults. Annals of İnternal Medicine 2015; 162: 133-40.

42. Cranney A, Horsley T, O'Donnell S et al. Effectiveness and safety of vitamin D in relation to bone health. Evid Rep Technol Assess (Full Rep) 2007; 158: 23-25.

43. Welch AK. The rising cost of vitamin D testing in Australia: time to establish guidelines for testing. Med J Aust 2012; 197: 90.

44. Rosen CJ, Abrams SA, Aloia JF et al. IOM committee members respond to Endocrine Society vitamin D guideline. J Clin Endocrinol Metab 2012; 97: 1146-52.

45. Wood CL, Cheetham TD.Vitamin D: increasing supplement use among at-risk groups (NICE guideline PH56). Archives of disease in childhood-Education \& practice edition 2015; 299-308.

46. CADTH Rapid Response Reports, in Vitamin D Testing in the General Population: A Review of the Clinical and CostEffectiveness and Guidelines. Canadian Agency for Drugs and Technologies in Health, Ottawa (ON).2015.

47. Mendy Moody R, Joyce Jackowski M. Are patients on oral chemotherapy in your practice setting safe? Clinical Journal of Oncology Nursing 2010; 14: 339.

48. Abrahamsem B, Masud T, Avenell A et al. Patient level pooled analysis of 68,500 patients from seven major vitamin D fracture trials in the US and Europe. British Medical Journal (BMJ) 2010; 340: 54-63.

49. Bischoff-Ferrari HA, Dawson-Hughes B, Staehelin HB et al. Fall prevention with supplemental and active forms of vitamin $D$ : a meta-analysis of randomised controlled trials. Bmj 2009; 339: 3692.

50. Tang BMP, Eslick GD, Nowson $C$ et al. Use of calcium or calcium in combination with vitamin D supplementation to prevent fractures and bone loss in people aged 50 years and older: a meta-analysis. The Lancet 2007; 370: 657-66.

51. Sözen T.TEMD Osteoporoz ve Diğer Metabolik Kemik Hastalıkları Çalışma Grubu. Osteoporoz. Sık Görülen Metabolik Kemik Hastalıkları Kullanım Klavuzu 2008: 9-25.

52. Ross AC, Taylor CL, Yaktine AL et al. Dietary reference intakes for adequacy: Calcium and Vitamin D.National Academies Press (US),2011.

53. Ross $A C$ et al (Editors). Institute of Medicine Committee to Review Dietary Reference Intakes for Vitamin D and Calcium, The National Academies Collection: Reports funded by National Institutes of Health, in Dietary Reference Intakes for Calcium and Vitamin D, National Academies Press (US), 2011. 
54. Holick MF, BinkleyNC et al. Evaluation, treatment, and prevention of vitamin D deficiency: an Endocrine Society clinical practice guideline. The Journal of Clinical Endocrinology \& Metabolism 2011; 96: 1911-30.

55. Agostoni C, Bresson JL, Fairweather Tait S et al. Scientific opinion on the tolerable upper intake level of eicosapentaenoic acid (EPA), docosahexaenoic acid (DHA) and docosapentaenoic acid (DPA): EFSA panel on dietetic products, nutrition and allergies (NDA).The Efsa Journal 2012; 10: 1-48.

56. Vidailhet $M$, Mallet $E$, Bocquet $A$ et al., Vitamin $D$ : still a topical matter in children and adolescents. A position paper by the Committee on Nutrition of the French Society of Paediatrics. Archives de pédiatrie 2012; 19: 316-28.

57. Whiting $\mathrm{SJ}$, Langlois KA, Vatanparast $\mathrm{H}$ et al. The vitamin $\mathrm{D}$ status of Canadians relative to the 2011 Dietary Reference Intakes: an examination in children and adults with and without supplement use. The American Journal of Clinical Nutrition 2011; 94: 128-35.

58. Nowson CA, McGrath JJ, Ebeling PR et al. Vitamin D and health in adults in Australia and New Zealand: a position statement. Med J Aust 2012; 196: 686-87.

59. Francis $R$, AsprayT, FraserW. Vitamin $D$ and Bone Health: A Practical Clinical Guideline for Patient Management. National Osteoporosis Society, 2013.

60. LeFevre ML. Screening for vitamin D deficiency in adults: U.S. Preventive Services Task Force recommendation statement. Ann Intern Med 2015; 162: 133-40.

61. de Koning L, Henne D, Woods $\mathrm{P}$ et al. Sociodemographic correlates of 25 -hydroxyvitamin D test utilization in Calgary, Alberta. BMC Health Serv Res 2014; 14: 339.

62. Kotta $\mathrm{S}$, Gadhvi $\mathrm{D}$, Jakeways $\mathrm{N}$ et al., "Test me and treat me"-attitudes to vitamin D deficiency and supplementation: a qualitative study. BMJ Open 2015; 5: 007401.

63. Henry HL, Bouillon R, Norman AW et al. 14th Vitamin D Workshop consensus on vitamin D nutritional guidelines. The Journal of Steroid Biochemistry and Molecular Biology 2010; 121: 4-6.

64. Heaney RP, Davies KM, Chen TC et al., Human serum 25-hydroxycholecalciferol response to extended oral dosing with cholecalciferol. The American Journal of Clinical Nutrition 2003; 77: 204-10.
65. Garland CF, French CB, Baggerly LL et al.Vitamin D supplement doses and serum 25-hydroxyvitamin $D$ in the range associated with cancer prevention. Anticancer Research 2011; 31: 607-11.

66. Mai S, Walker G, Vietti Ret al. Acute Vitamin D(3) Supplementation in Severe Obesity: Evaluation of Multimeric Adiponectin. Nutrients 2017; 9

67. Mai S, Walker G, Vietti R, Cattaldo S, Mele C . The effect of vitamin D supplement on the score and quality of sleep in 20-50 year-old people with sleep disorders compared with control group. Nutr Neurosci 2017; 1-9.

68. Bilici ME. 10-18 yaş arası d vitamini eksikliği olan obez adolesanlarda 2000 IU/gün D vitamini tedavisinin insülin direnci ve kardiyovasküler risk parametreleri üzerine etkisi. Sağlık Bilimleri Üniversitesi, Çocuk Sağlığı ve Hastalıkları Anabilim Dalı, Endokrinoloji Bilim Dalı. 2016.

69. Tambova AK. Kronik böbrek hastalığında d vitamininin trombosit fonksiyonları üzerine etkisi. Eskişehir Osmangazi Üniversitesi, İç Hastalıkları Anabilim Dalı. Eskişehir, 2015.

70. Moreira-Pfrimer LDF, Pedrosa MAC et al. Treatment of vitamin D deficiency increases lower limb muscle strength in institutionalized older people independently of regular physical activity: a randomized double-blind controlled trial. Ann Nutr Metab 2009; 54: 291-300.

71. Gallagher JC, Sai A, Templin T. Dose response to vitamin D supplementation in postmenopausal women: a randomized trial. Ann Intern Med 2012; 156: 425-37.

72. Dong Y, Stallmann-Jorgensen IS et al. A 16-week randomized clinical trial of 2000 international units daily vitamin D3 supplementation in black youth: 25-hydroxyvitamin D, adiposity, and arterial stiffness. J Clin Endocrinol Metab 2010; 95: 4584-91.

73. Ganmaa D, Stuart JJ, Sumberzul N et al. Vitamin D supplementation and growth in urban Mongol school children: Results from two randomized clinical trials. PLoS One, 2017; 12. 